\title{
Bionic Eye from the Point of View of Functional Magnetic Resonance and Electrophysiological Examination - Review
}

\author{
Lestak Jan $^{1 *}$, Fus Martin ${ }^{1}$, Rozsival Pavel ${ }^{2}$, Karel Ivan ${ }^{1,2}$, Brozkova Marketa ${ }^{2}$, Almesmari Basma $^{2}$ \\ and Jiraskova Nada ${ }^{2}$ \\ ${ }^{1}$ Ophthalmology Clinic, CTU in Prague, Czech Republic \\ ${ }^{2}$ Department of Ophthalmology, Charles University and University Hospital in Hradec Kralove, Czech Republic
}

*Corresponding author: Lestak Jan, Ophthalmology clinic Faculty of Biomedical Engineering, CTU in Prague, V Hurkach 1296/10, 158 00 Prague 5, Czech Republic.

To Cite This Article: L Jan, F Martin, R Pavel, K Ivan, B Marketa, et al., Bionic Eye from the Point of View of Functional Magnetic Resonance and Electrophysiological Examination - Review. 2020 - 8(5). AJBSR.MS.ID.001301. DOI: 10.34297/AJBSR.2020.08.001301.

Received: March 11, 2020; Published: 耕 April 22, 2020

\begin{abstract}
The aim of the study was to show not only a possible visual replacement in patients with loss of sight, but also to discuss its efficiency. The study is focused on the issue of transmission of electrical voltage changes in the visual pathway under physiological and pathological conditions. In particular, it points to the feedback autoregulatory damage, not only of the primarily altered cellular structures, but also of all other structures localised both horizontally and vertically. Based on the results of the functional magnetic resonance imaging and electrophysiological methods, it demonstrates the pathology of the entire visual pathway in three important eye diseases: pigmentary retinal dystrophy, age-related macular degeneration, and glaucoma. The study also provides an overview of possible systems used to replace loss of vision, ranging from epiretinal, subretinal, suprachoroidal implants to stimulation of the optic nerve, lateral geniculate nucleus and visual cortex. Regarding the pathophysiology of neurotransmission, it is assumed that recovery of sight using these systems is not possible.
\end{abstract}

Keywords: Neurotransmission; Pigmentary Retinal Dystrophy; Age-Related Macular Degeneration; Glaucoma; Bionic Eye; Functional Magnetic Resonance Imaging; Electrophysiological Tests

Abbreviations: AMD: Age-Related Macular Degeneration; AMPA: $\alpha$-amino-3-hydroxy-5-methyl-4-8 isoxazolpropionate; Ca: Calcium; EAAT: Excitatory Amino Acid Transporter; ERG: Electroretinogram; fMRI: Functional Magnetic Resonance Imaging; GA: Geographic Atrophy; GLAST: Glutamate Aspartate Transporter; GS: Glutamine Synthetase; LE: Left Eye; Mg: Magnesium; MC: Muller Cells; NMDA: N-methyl-D-Aspartate; PERG: Pattern Electroretinogram; PVEP: Pattern Visual Evoked Potentials; RE: Right Eye; RP: Retinitis Pigmentosa; VA: Visual Acuity

\section{Introduction}

Worsening of sight and blindness remain significant problems of general healthcare worldwide. The World Health Organization (WHO) estimates that worldwide there are approximately 253 million people with impairment of sight. In 2015, 36 million were blind and 217 million had moderate to severe visual impairment. Approximately $80 \%$ of the cases of blindness can be avoided if preventive measures are taken or if they are diagnosed and treated early [1]. Although most blind and visually impaired people live in low-income countries, it is important to note that blindness caused by eye diseases is also an important healthcare problem in Europe [2]. In the last quarter of a century, this condition has led researchers in medicine and biomedical engineering to the development of different models of visual prostheses. According to Fernandez et al., approximately 140000 blind people in industrial countries could benefit from a bionic eye [3].

Neurotransmission in the Visual Pathway - Physiology

After the impact of light on the retina, a chemical change occurs in the outer photoreceptor segments (the cis-retinal form becomes the transform). This causes their hyperpolarisation [4]. 
Hyperpolarisation of photoreceptors during synaptic transmission causes the release of glutamate from the presynaptic part to the synaptic cleft and its subsequent binding to the receptors located on the membrane of the postsynaptic neuron [5]. The glutamate receptors are present not only in the photoreceptors but also in the horizontal and bipolar cells, as well as in the retinal ganglion cells [6]. Glutamate is bound to the receptors, which have been named based on their selective agonists. N-methyl-D-aspartate is a typical agonist for the NMDA receptors; $\alpha$-amino-3-hydroxy-5-methyl-4-8 isoxazolpropionate for the AMPA receptors, and kainate for the third type - the kainate receptors. AMPA and kainate receptors are also called non-NMDA [7].

NMDA receptors represent ion channels permeable for calcium ions (Ca). Under normal membrane potential, the flow of calcium through NMDA receptors is blocked by the magnesium (Mg) ions. This block can be eliminated by strong depolarisation [8]. Glutamate is a predominant excitation neurotransmitter in the retina and brain of mammals [9]. After induction, the post-synaptic excitation potential glutamate must instantly be removed from the synaptic cleft. In the mammalian central nervous system, glutamate is removed from the synapsis primarily by glutamate transporters, i.e. excitatory amino acid transporter (EAAT) and glutamate aspartate transporter (GLAST), as glutamate transporters to the Muller cells (MC) and glutamine synthetase (GS) as an enzyme converting glutamate to glutamine in the MCs $[10,11]$. In glial cells, glutamate is subsequently changed to glutamine. Glutamine no longer acts as a neurotransmitter and can thus be released back to the synapse, from which it is subsequently taken up by the presynaptic neuron that converts it back to glutamate [12].

To date, there is no evidence of the presence of an enzyme that would convert glutamate directly in the synapse [13]. Concentration of free glutamate in the synaptic cleft during synaptic transmission is about $1.1 \mathrm{mM}$, but its concentration decreases rapidly. In NMDA receptors, it disintegrates within $1.2 \mathrm{~ms}$. However, glutamate dissociates more rapidly from AMPA receptors. Thus, the time course of free glutamate predicts that dissociation contributes to the breakdown of the post-synaptic flow mediated by AMPA receptors. Otherwise the voltage-gated channels would be opened [5].

\section{Neurotransmission in the Visual Pathway - Pathol- ogy}

One of the first stimuli that led us to investigate visual pathway processes was the simultaneous measurement of the pattern electroretinogram (PERG) and the pattern visual evoked potentials (PVEP) in a 20-year-old healthy individual, first at intraocular pressure (NOT) of $15 \mathrm{mmHg}$ and then following its increase to 40 mmHg. To our surprise, neurotransmission was blocked at the level of the retinal ganglion cells, while PVEP changed slightly (Figure 1). This fact did not correspond to the current definitions of glaucoma consisting of impairment of the retinal ganglion cell axons with excavation on the optic disc and changes in the visual field. With the blockade of transmission on the level of the ganglion cells, we expected an inadequate or at least abnormal PVEP response, measurements were taken in 1987 [14] (Figure 1).

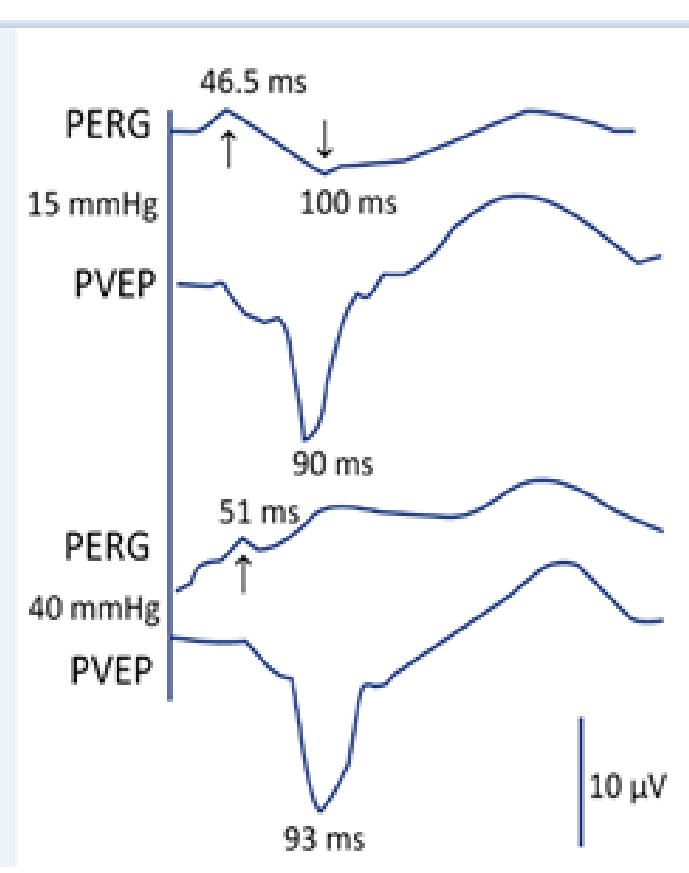

Figure 1: The upper curve (PERG) and the PVEP below at a normal IOP. The arrows show latency of the cycles, whose amplitude occurs by a response of the retinal ganglion cells. The lower curves show the status after increase of the IOP to $40 \mathrm{mmHg}$ [14].

Two questions remain unanswered. Why did the retinal ganglion cells not respond, and what happened to the central visual pathway when, after the blockade at the level of the retinal ganglion cells, we got an almost normal response in the brain? Why did we not notice the first changes at the level of the retinal ganglion cell axons, when all the previously available glaucoma definitions state that this is the case? Shou et al. quantitatively studied alpha and beta retinal ganglion cells after acute elevation of IOP. According to their analysis, cell density, body size, maximum dendritic field diameter, total dendritic length, and the number of dendritic bifurcation branches decreased significantly in glaucoma eyes compared to the healthy group. Loss of cells and shrinkage of dendrites in the types of alpha ganglion cells was more pronounced compared to the beta cells. The density of all types of cells in the retina and lateral geniculate body decreased in time if IOP was increased, with the loss of cells being more significant in the large cells (alpha) compared to the small (beta) cells [15].

There is only one explanation for the second question of what happened to the visual pathway when IOP increases. Following stabilisation of the binocular functions, the visual cortex is set up to receive a certain amount of action potentials. When this amount is decreased at any level from the photoreceptors up to the cortical 
cells, we will start to find out at which level this lesion occurred by means of the feedback processes [16-19].

There are two possibilities for recovery of the action potentials coming to the brain to the baseline values. The first is to wash out a higher amount of the neurotransmitter and the other is to leave this neurotransmitter in the synaptic cleft for a longer time. Both possibilities have been experimentally proven in glaucoma. In the vitreous humour of glaucoma eyes of experimental animals, the glutamate value (27 microM) was up to 3 -fold higher than in the control group. These values are toxic both for the layer of ganglion cells and for the internal plexiform layer [20].

The GLAST and GS values were increased following increase of the IOP in rats after 3 weeks. The number of the ganglion cells 4-60 days following the increase of IOP was reduced by 6 to $44 \%$ [21]. In addition, the glutamate transporter may begin to work in a reverse mode and transfer glutamate and sodium from the cell back to the synaptic cleft. Thus, flushed glutamate comes only in a small portion from the synaptic pouches and most of it comes from the cytosol to which it was previously drained [22]. During the longterm effects of glutamate on non-NMDA receptors, an increase of the postsynaptic potential and opening of the voltage-controlled receptors which are normally closed by magnesium $(\mathrm{Mg})$ occurs, which prevents Ca from entering the cell. This process occurs in all cells with glutamate receptors. Therefore, not only retinal ganglion cells but also cells in the inner core layer and photoreceptor layer are damaged in glaucoma [23].

Excessive calcium flow into the cell through the NMDA-voltage channel may induce hypoxia, hypoglycaemia, etc. Under these conditions, the level of glutamate in the synaptic cleft remains elevated for a long time, with sustained activation of the NMDA receptors, resulting in the intracellular calcium concentrations which are cytotoxic. Hence, this process is typical not only for impairment caused by glaucoma [24]. By glutamate binding, the NMDA receptor begins to release calcium into the cell. This can have a double effect on a cell. Under physiological conditions, it can provide the signal needed for survival of the nerve cell, and by contrast, in pathological conditions, it can have an excitotoxic effect. This is because excessive activation of glutamate receptors has many detrimental effects on the cell, including reduced ability to buffer the influent calcium, produce oxygen radicals, activate nitric oxide synthesis which may lead to cytoskeletal degradation and excessive activation of calcium-dependent enzymes [25].

For these reasons, free cytosolic calcium needs to be drained, which is ensured by the mitochondria and partly by the endoplasmic reticulum. In particular, mitochondria are important for maintaining a low concentration of cytosolic calcium and their dysfunction can lead to cell death by disrupting calcium homeostasis, releasing proapoptotic factors, or increasing production of oxygen radicals [26]. Excessive production of oxygen radicals leads to the formation of oxidative stress, which causes damage to nucleic acids, proteins, lipids, and can lead to the opening of mitochondrial channels, which in turn leads to the formation of additional oxygen radicals, energetic failure and release of pro-apoptotic factors such as cytochrome $\mathrm{c}$ into the cytoplasm. Oxidative stress is a major factor in the pathological neuronal damage involved in both acute and chronic central nervous system damage in many neurodegenerative diseases [25].

Other pro-apoptotic factors have been found which are released by the massive entry of calcium into the cell, such as the p38 MAP kinase pathway or the c-Jun $\mathrm{N}$-terminal kinase. Free cytosolic calcium can also induce apoptosis by activating calcineurin and calpain, which are calcium-dependent apoptotic proteases [27].

When signal pathways which lead to the death of a nerve cell are activated, the energy reserves of the cell decide on the mode of cell death. If the cell has enough energy, a cascade of reactions leading to programmed cell death - apoptosis - can be triggered during which the cell morphology, condensation and fragmentation of the DNA, cytoskeletal proteolysis, and exposure of other antigens to the cell surface occur. A neuron is therefore removed, in order to minimise the inflammatory reaction, and its removal by glial cells is facilitated. However, if a cell has a lack of energy to cause programmed cell death, it dies of necrosis.

However, enough energy does not only decide on the mechanism of cell death, butalso on whether it occurs at all, because if the energy is deficient, the concentration of glutamate that would not normally be excitotoxic can cause it. This is because neurons and glial cells removing glutamate from the synapse need sufficient energy [2830]. However, neurons are not passive, and they resist excitotoxicity by several mechanisms. One of these is the removal of glutamate from the synapse and calcium from cytosol. Another mechanism is to ensure more energy to the nervous system, which is done by incorporating more glucose transporters into the membranes, or by using lactate as a source of energy. The energy crisis is signalled by, among other things, an increased amount of adenosine produced by the consumption of adenosine triphosphate. Adenosine may function as a retrograde neurotransmitter and prevent the release of additional glutamate. Thus, it acts similarly to the intracellular feedback loops which provide inhibition of a receptor, e.g. with increasing concentration of the cytosolic calcium, glutamate, and protons. A defensive hyperpolarisation of neurons occurs by means of the potassium channels, whose opening is triggered by ATP depletion or an excess of cytosolic calcium. In addition, the synthesis of antioxidative oxygen enzymes destroying the oxygen radicals which develop during excitotoxicity (Sapolsky, 2000) may be increased [31].

Whetheractivation of the NMDA receptor results in excitotoxicity or neuroprotection is also probably influenced by its localisation in addition to the stimulation intensity, since NMDA receptors 
may occur both synaptically and extrasynaptically. Activation of the synaptic NMDA receptors appears to have a predominantly neuroprotective effect, while activation of extrasynaptic NMDA receptors triggers cell death signalling pathways [32].

As mentioned above, glutamate is the major excitatory neurotransmitter in the vertebrate brain and therefore it is necessary to maintain its levels in the physiological range (9). Under normal conditions, the concentration of glutamate in the synaptic cleft may increase up to $1 \mathrm{mM}$, from which it is then taken up in milliseconds and its concentration is again reduced [5]. However, if its amount in the vicinity of the synaptic cleft cannot be reduced or is even exceeded, the neurons undergo apoptosis or necrosis [33]. Excitotoxicity as such was first described by Olney [9]. It involves excessive activation of glutamate receptors in the CNS. Glutamate neurotoxicity caused by NMDA receptor activation was suggested only in a later study [24]. After intense activation of the NMDA receptors, glutamate excess for the neurons may be toxic in several acute injuries, including stroke [34] or epilepsy [35].

\section{The Most Common Ophthalmological Diseases for Which a Bionic Eye is Indicated}

As mentioned above, any lesion of the nerve cells in the visual pathway can damage not only the cellular nerve structures located horizontally, but also vertically. Another important finding resulting from this information, as well as from the visual pathway anatomy, is that unilateral lesions also cause damage to contralateral nerve structures [36-38]. Therefore, it is not possible to predict the improvement of visual functions to usable values when implanting visual neuroprothesis.

As the bionic eye is most commonly indicated in patients with retinitis pigmentosa (RP)and age-related macular degeneration (AMD), we focus mainly on these two diagnostic groups. A prerequisite for the effectiveness of this system is the preservation of the integrity of the middle and inner retinal structures, the visual pathway and the subcortical and cortical centres in the brain [39].

$\mathrm{RP}$ is a disease that primarily affects the rods and cones and retinal pigment epithelium located beneath. The inner core and plexiform layers, ganglion cells and their fibres undergo degeneration and are replaced by gliotic tissue. These changes may be visible in the later stage of the disease [40].

Electrophysiological findings in sight show that, already in the early phases of the disease, the alteration affects not only the rods but also the macular retinal structures including the ganglion cells. This also results in impairment of the visual nerve and visual cortex in the brain. Electrophysiological findings of impairment of the visual pathway have also been verified by tractography of the brain [41-42].

\section{Medical Findings of FMRI in Various Diseases}

\section{Retinitis Pigmentosa}

A male (63 years) with RPof both eyes had VARE: 0.2 naturally, VALE: 0.3 naturally. Correction did not improve the sight. Perimetric examination showed a concentric narrowing of the visual fields to 10 and 5 degrees, respectively. Electrophysiological examination (according to ISCEV methodology) showed bilaterally missing response. Both in ERG, PERG and PVEP. At the above stated visual functions, fMRI following stimulation of each eye separately and both eyes concurrently did not find any brain activity [43]. Functional MRI examinations were carried out on the Philips Achieva 3T TX MR system (Philips Healthcare, Eindhoven, Netherlands) with a magnetic field strength of 3 Tesla, using the blood oxygen level dependent (BOLD) contrast. A standard 32-channel head coil was used and each measurement was performed with gradient-echo echo-planar imaging sequence.

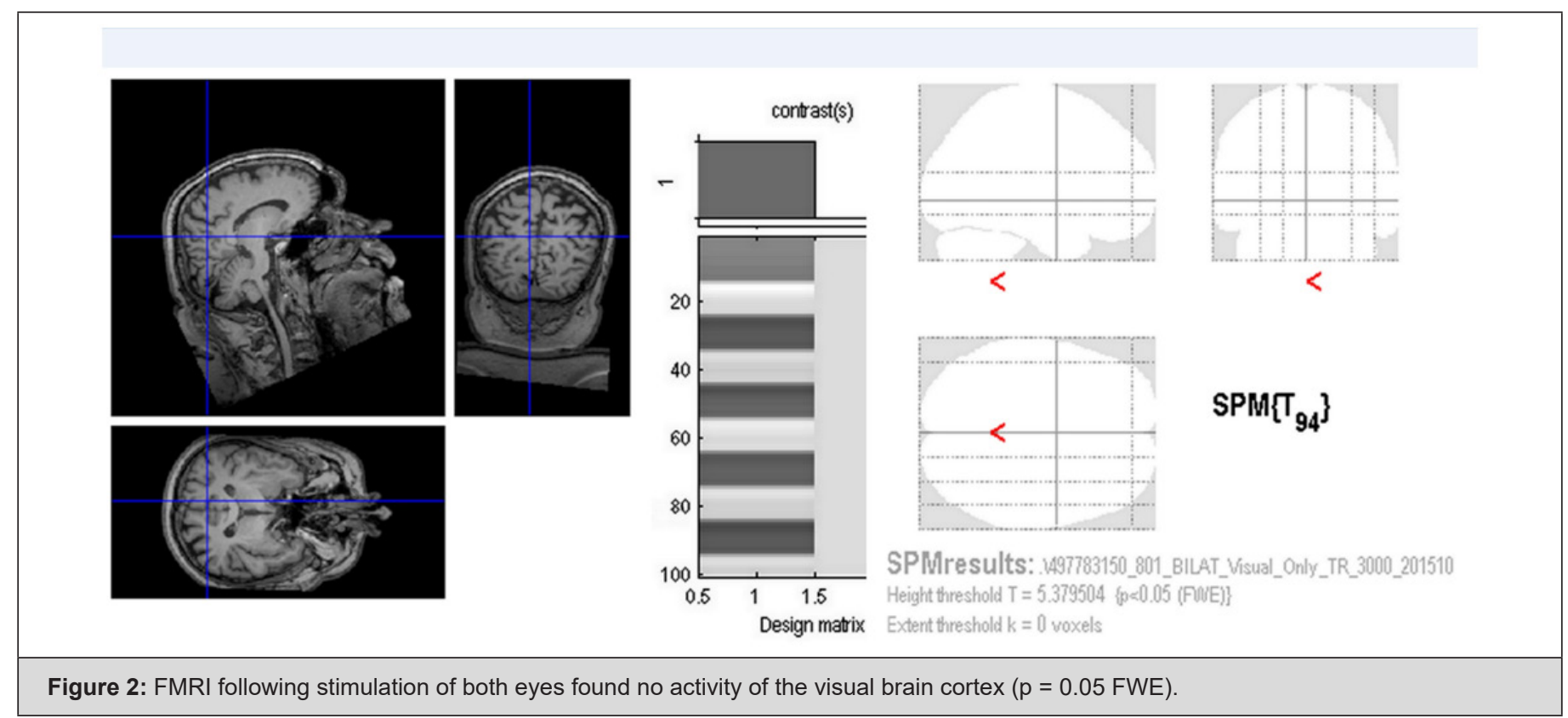


$\left(\mathrm{TR} / \mathrm{TE}=3000 / 30 \mathrm{~ms}\right.$, spatial resolution of $\left.2 \times 2 \times 2 \mathrm{~mm}^{3}\right)$. Optical stimulation was performed by a black/white checkerboard alternated with its negative image with a frequency of $2 \mathrm{~Hz}$. The visual size of the black and white checkerboard was $25.8 \times 16.2$ degrees. The measurements consisted of a sequence of five 30 -second active phase periods and five resting periods of the same length (each of 10 dynamic scans). During the resting phase, a static crosshair situated in the centre of the visible field was projected for the view fixation. In total, every measurement included 100 dynamic scans and took 5 minutes. Each eye was examined by means of separate fMRI measurement (LE, RE) and then both eyes together (LE+RE). Evaluation of the task-related fMRI was done using General Linear Model (GLM) in SPM12. After standard preprocessing (Realignment, Normalisation to MNI space, smoothing to $6 \times 6 \times 6 \mathrm{~mm}^{3}$ ), GLM statistic with final $\mathrm{p}=0.05$ with Family Wise Error (FWE) correction was done (Figure 2).

Castaldi et al. $[44,45]$. Machado et al. found alteration of fMRI

A

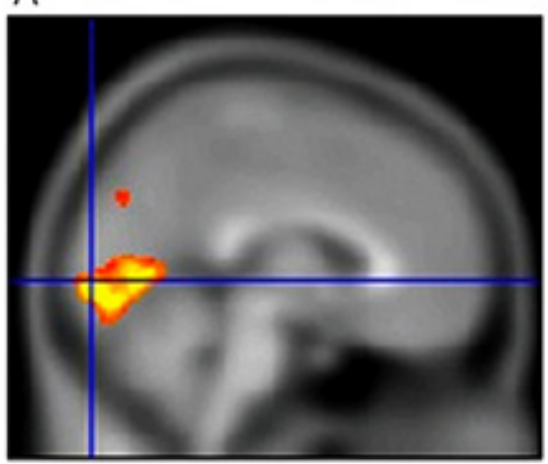

B

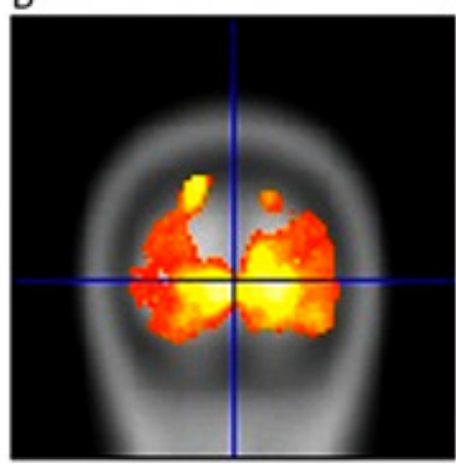

in RP and others confirmed decrease of visual cortex volume in patients with RP [46]. (Figure 2).

\section{Age-related Macular Degeneration (AMD)}

In AMD, the impairment of the photoreceptors (cones) causes decrease of the retinal ganglion cells. It was found that the number of retinal ganglion cells is significantly lower in AMD compared to the control eyes. The loss is higher in the wet form of AMD compared to geographic atrophy (GA). Compared to the control eyes, a loss of the retinal ganglion cells was seen in GA of up to $30.7 \%$ [47]. In the wet form of AMD it was reported at $47 \%$ [48]. Isolated central lesions in AMD lead to impairment of the visual cortex in the brain.

We examined 10 patients with the wet form of AMD ( 9 females and 1 male), with an average age of 74.7 years (58-85 years) at different stages of bilateral disability. The patients did not suffer from other ophthalmological or neurological diseases. Using fMRI, we found a significant decrease of voxel activity compared to the control group ( $\mathrm{p}=0.024)$ [49] (Figure $3 \& 4$ ).

Figure 3: Activity of the visual centre in the brain in a healthy 50-year-old female. VARE: 1.0 naturally, VALE: 1.0 naturally. Sagittal section (A), (B) transverse section and coronal section (C)following concurrent stimulation of both eyes show normal fMRI values of 6815 voxel (usual correct threshold $\mathrm{p}=0.05$ with FWE correction). Both eyes were stimulated simultaneously.

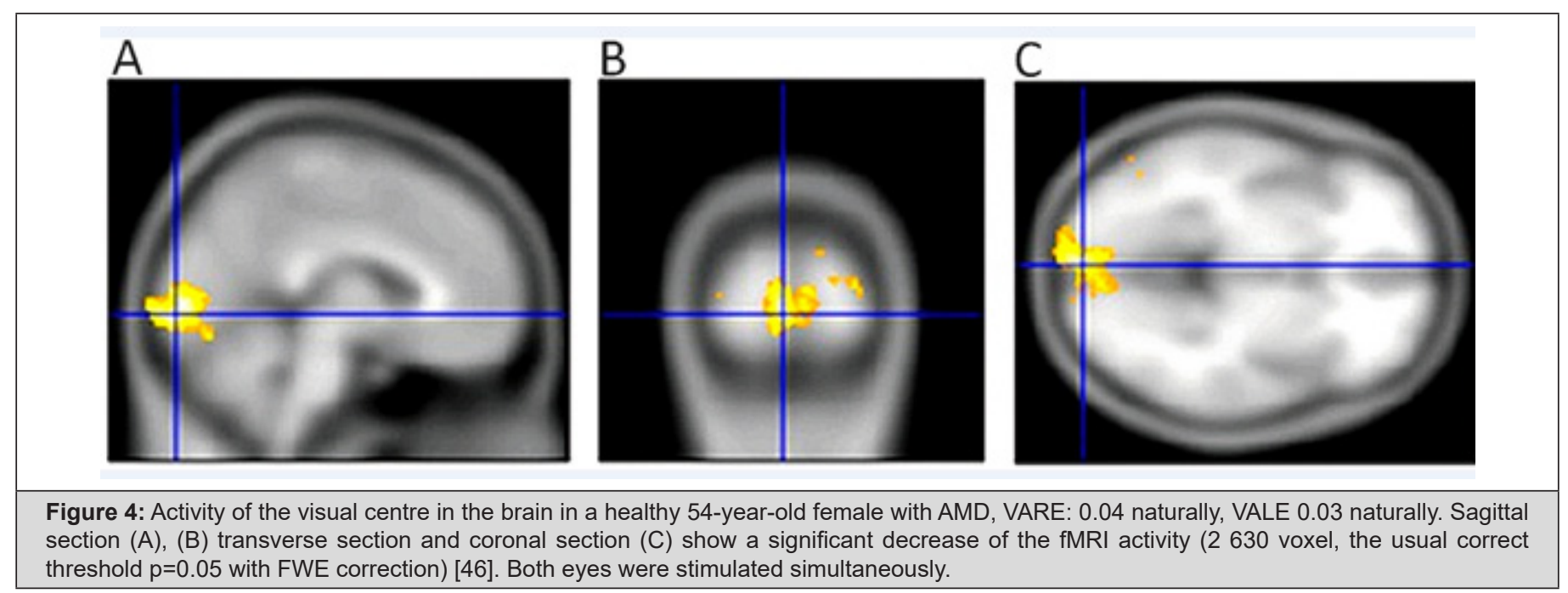




\section{Hypertension Glaucoma}

Hypertensive glaucoma damages the retinal ganglion cells and consequently the visual pathways, including the visual headquarters of the brain. Similarly, lower retinal structures (bipolar cells and photoroceptors) are damaged. We examined 9 patients with different stages of high-tension glaucoma (3 females aged 41-65 and 6 males aged 40-73) by fMRI. The examination was performed according to the above methodology, but we used black and white hemipol for stimulation, followed by the same examination with blue-yellow stimulation. Both eyes were stimulated simultaneously. The sum of sensitivities in the homolateral halves of the visual fields (ranging from 0-22 degrees, see table I) was compared to the extent of fMRI contralateral activity of the visual cortex. This group was compared with a group of eight healthy subjects ( 3 females aged 23-46 and 5 males aged 23-65).
The resulting correlation coefficient between the right half of the visual field and fMRI activation extent on the left was 0.667 $(p<0.05)$. The correlation coefficient between the left halves of the visual fields and fMRI activation on the right was 0.767 with $\mathrm{p}<$ 0.016 [50].

The mean value of the difference in the number of activated voxels using the BW vs. YB stimulation is $59 \%$ for glaucoma patients while for the healthy controls it is only $2 \%$. Statistical maps of $\mathrm{BW}>\mathrm{YB}$ and $\mathrm{BW}<\mathrm{YB}$ differences for the patients and controls were thresholded at an uncorrected threshold of $\mathrm{p}=0.001$ at individual level (for each subject) and the numbers of voxels were statistically compared between all groups using t-test. While the BW>YB difference between the control group and the patients differed by the statistically significant 1.606 voxels $(p=0.039)$, no difference was found for $\mathrm{BW}<\mathrm{YB}(\mathrm{p}=0.18)$ [50]. (Table 1).

\begin{tabular}{|c|c|c|c|}
\hline & Average $[\mathrm{dB}]$ (sum of sensitivities) & Median & Standard deviation \\
\hline \multicolumn{4}{|c|}{ Right halves of visual fields } \\
\hline Control group: & 2200.3 & 2196.5 & 59.6 \\
\hline Patients: & 1367.2 & 1493 & 532.5 \\
\hline \multicolumn{4}{|c|}{ Right halves of visual fields } \\
\hline Control group: & 2165.8 & 2176 & 69.5 \\
\hline Patients: & 1396.6 & 1615 & 611.2 \\
\hline \multicolumn{4}{|c|}{ fMRI of the left occipital hemisphere (voxel numbers) } \\
\hline Control group: & 4181.5 & 3445.5 & 2366 \\
\hline Patients: & 2981.7 & 2550 & 1531.2 \\
\hline \multicolumn{4}{|c|}{ fMRI of the right occipital hemisphere (voxel numbers) } \\
\hline Control group: & 4414.6 & 4093 & 2280.8 \\
\hline Patients: & 2995.6 & 2232 & 1983.6 \\
\hline
\end{tabular}

Even with these experiments we have shown that with the progression of glaucoma there is an alteration of the cortical headquarters in the brain. This implies that retinal disorder, whether at the level of photoreceptors or ganglion cells, leads to damage if visual centers in the brain, particularly in PDR. This disease is most often indicated for the implantation of visual neuroprostheses.

\section{Bionic Eye}

Currently, four systems of bionic eye have received permission for launch on the European and US markets. Many others have undergone preclinical and clinical trials which reflect the established safety profile for sustained stimulation. This progress points to an effort to assist blind patients in their hopes of real and measurable aid [51]. In the last quarter of a century, attention has been paid to retinal neuroprostheses with active stimulation (with an external source of energy).

This is a small camera system, placed in glasses, that transmits the captured information to a video chip. This video chip translates the information into electrical voltage changes and transmits these to a retinal implant consisting of a certain number of electrodes to stimulate the retinal cells. Photodiodes built directly into the microchip can be used instead of the camera. Even those require an external source of energy. The microchip with electrodes can be implanted epiretinally, subretinally or suprachoroidally. Similarly, the axons of these cells may also be stimulated by electrodes placed in the optic nerve sheath, or even in the lateral geniculate body, which may be stimulated by deep electrodes, or more recently by a cluster of microelectrodes, or in the visual cortex by surface or deep electrodes, according to Philip et al. [52]. The most common types of epiretinal prostheses include the Argus II Retinal Prosthesis System. The chip consists of 60 microelectrodes which cover 20 degrees of the visual field. The best visual acuity was achieved in a patient with a decrease of visual acuity $20 / 1260(0,016)$. When Argus II was used, the visual acuity was improved to $20 / 1000(0,02)$ $[53,54]$. Other epiretinal systems include the Intelligent Retinal Implant System II (IRIS II) [55-57], EPI-RET3 Retinal Implant System [58]. These systems can theoretically be disadvantageous, as they rule out processing of the electric voltage changes in the bipolar, horizontal and amacrine and ganglion cells. I deliberately 
use the term "theoretically" because, as stated before, vertical damage occurs in the photoreceptor lesions Therefore, a complex processing of the electrical changes in the retina is insufficient in advanced dystrophies. A Subretinal Chip is placed between the pigment epithelium and photoreceptors. It detects light, that is then transferred to the electrical potential and this is delivered to the retinal neurons. This system includes the Boston Retinal Implant Project (BRIP) [59], Artificial Silicon Retina [60,61], Alpha IMS and AMS [39,62], Photovoltaic Retinal Implant (PRIMA) [63-65].

\section{Suprachoroidal Prostheses}

The picture detects the chip, or the processed image detected by the camera is brought to it. The chip alone is implanted suprachoroidal because of the minimal iatrogenic impairment of the retina. These systems include Bionic Vision Australia (BVA) [66-71], Suprachoroidal-transretinal Stimulation [72-75].

\section{Conclusion}

Pathophysiology of neurotransmission in the visual pathway does not, in theory, allow for the successful use of a bionic eye. Therefore, the direction of development should be pointed towards a different method.

\section{Funding}

This work was supported by Charles University Prague, Czech Republic (PROGRESS Q40/07).

\section{Availability of Data and Materials}

All data generated or analysed during this study are included in this published article or are available from the corresponding author.

\section{Ethics approval and Consent to Participate}

All patients included in the present study consented to participate, and the study protocol conformed to the principles outlined in the Declaration of Helsinki within the ethic committee.

\section{Disclaimer}

The authors of the study state that the origin and topic of the expert message and its publication are not in conflict of interest and the study is not supported by any pharmaceutical company.

\section{References}

1. Bourne RRA, Flaxman SR, Braithwaite T (2017) Magnitude, temporal trends, and projections of the global prevalence of blindness and distance and near vision impairment: a systematic review and metaanalysis. Lancet Glob Health 5(9): 888-897.

2. Szabo D, Sandor GL, Toth G (2018) Visual impairment and blindness in Hungary. Acta Ophthalmol 96: 168-173.

3. Pelayo F, Romero S, Bongard M, Marin C, Merabet L, et al. (2005) Development of a cortical visual neuroprosthesis for the blind: the relevance of neuroplasticity. J Neural Eng 2(4): 1-12.
4. Kiser PD, Golczak M, Maeda A, Palczewski K (2012) Key enzymes of the retinoid (visual) cycle in vertebrate retina. Biochim Biophys Acta 1821(1): 137-151.

5. Clements JD, Lester RA, Tong G, Jahr CE, Westbrook GL (1992) The time course of glutamate in the synaptic cleft. Science 258: 1498-1501.

6. Shen Y, Liu XL, Yang XL (2006) N-methyl-D-aspartate receptors in the retina. Mol Neurobiol 34(3): 163-179.

7. Kew JN, Kemp JA (2005) Ionotropic and Metabotropic Glutamate Receptor Structure and Pharmacology. Psychopharmacology 179: 4-29.

8. Johnson JW, Ascher P (1990) Voltage-dependent block by intracellular $\mathrm{Mg}^{2+}$ of N-methyl-D-aspartate-activated channels. Biophys J 57(5): 1085-1090.

9. Olney JW, Sharpe LG (1969) Brain Lesions in an Infant Rhesus Monkey Treated with Monsodium Glutamate. Science 166(3903): 386-388.

10. Rothstein JD, Martin L, Levey AI, Dykes Hoberg M, Jin L, et al.( 1994) Localization of neuronal and glial glutamate transporters. Neuron 13(3): 713-725.

11. Amara SG, Fontana AC (2002) Excitatory amino acid transporters: keeping up with glutamate. Neurochem Int 41(5): 313-318.

12. Danbolt NC (2001) Glutamate uptake. Prog Neurobiol 65:1-105.

13. Huang YH ,Bergles DE(2004) Glutamate transporters bring competition to the synapse. Curr Opin Neurobiol 14(3): 346-352.

14. Lestak J, Tintera J, Kyncl M, Svata Z, Rozsival P, et al.(2013) High Tension Glaucoma and Normal Tension Glaucoma in Brain MRI. J Clin Exp Ophthalmol 4: 4 .

15. Shou T, Liu J, Wang W, Zhou Y, Zhao K, et al. (2003) Differential dendritic shrinkage of alpha and beta retinal ganglion cells in cats with chronic glaucoma. Invest Ophthalmol Vis Sci 44(7): 3005-3010.

16. Sherman SM, Guillery RW (2006) Exploring the Thalamus and Its Role in Cortical Function.

17. Shou TD (2010) The functional roles of feedback projections in the visual system. Neurosci Bull 26(5): 401-410.

18. Briggs F, Usrey WM (2011) Corticogeniculate feedback and parallel processing in the primate visual system. J Physiol 589(1): 33-40.

19. Thompson AD, Picard N, Min L, Fagiolini M, Chen C (2016) Cortical Feedback Regulates Feedforward Retinogeniculate Refinement. Neuron 91(5): 1021-1033.

20. Vorwerk CK, Gorla MS, Dreyer EB (1999) An experimental basis for implicating excitotoxicity in glaucomatous optic neuropathy. Survey of Ophthalmology 43: 142-150.

21. Woldemussie E, Wijono M, Ruiz G (2004) Muller cell response to laserinduced increase in intraocular pressure in rats. Glia 47: 109-119.

22. Grewer C, Gameiro A, Zhang Z, Zhen T, Braams S,et al. (2004) Glutamate forward and reverse transport: from molecular mechanism to transporter-mediated release after ischemia. IUBMB Life 60: 609-619.

23. Pavlidis M, Stupp T, Naskar R, Cengiz C, Thanos S, et al. (2003) Retinal Ganglion Cells Resistant to Advanced Glaucoma: A Postmortem Study of Human Retinas with the Carbocyanine Dye DiI. Invest Ophthalmol Vis Sci 44: 5196-5205.

24. Choi DW, Koh JY, Peters S (1988) Pharmacology of glutamate neurotoxicity in cortical cell culture: attenuation by NMDA antagonists. J Neurosci 8: 185-96.

25. Dong X, Wanf Y, Qin Z. Molecular mechanisms of excitotoxicity and their relevance to pathogenesis of neurodegenerative diseases. Acta Pharmacol 30: 379-87.

26. Orrenius S(2004) Mitochondrial regulation of apoptotic cell death. Toxicol Lett 149: 19-23. 
27. Hardingham GE, Bading H (2003) The Yin and Yang of NMDA receptor signalling. TRENDS in Neurosciences 26: 81-89.

28. Beal M, Hyman B, Koroshetz W (1993) Do defects in mitochondrial energy metabolism underlie the pathology of neu- rodegenerative diseases? Trends Neurosci 16: 125-131.

29. Turski L, Turski W (1993) Towards an understanding of the role of glutamate in neurodegenerative disorders: Energy metabolism and neuropathology. Experientia 49: 1064-1072.

30. Rossi D, Oshima T, Attwell D (2000) Glutamate release in severe brain ischaemia is mainly by reversed uptake. Nature 403: 316-321.

31. Sapolsky RM (2000) The Possibility of Neurotoxicity in the Hippocampus in Major Depression: A Primer on Neuron Death. Biol Psychiatry 48: 755-765.

32. Hardingham GE, Bading H (2010) Synaptic versus extrasynaptic NMDA receptor signalling: implications for neurodegenerative disorders. Nat Rev Neurosci 11: 682-696.

33. Ankarcrona M, Dypbukt JM, Bonfoco E, Zhivotovsky B, Orrenius S, et al. (1995) Nicotera P. Glutamate-Induced Neuronal Death: A Succession of Necrosis or Apoptosis Depending on Mitochondrial Function. Neuron 15: $961-973$.

34. Lipton SA, Rosenberg PA (1994) Excitatory Amino Acids as a Final Common Pathway for Neurologic Disorders. The New England Journal of Medicine 330: 613-622.

35. Olney J, Collins RC, Sloviter RS (1986) Excitotoxic Mechanisms of Epileptic Brain Damage." Advances in Neurology 44: 857-877.

36. Kyncl M, Lestak J, Tintera J, Haninec P(2019)Traumatic optic neuropathy - a contralateral finding (case report). Experimental and Therapeutic Medicine 17: 4244-288.

37. Lestak J, Haninec P, Kyncl M, Tintera J (2019) Optic nerve sheath meningioma-findings in the contralateral optic nerve tract: a case report. Molecular and Clinical Oncology p. 17.

38. Lestak J, Kalvodova B, Karel I, Tintera J (2019) Functional magnetic resonance imaging following epimacular and internal limiting membrane peeling - ipsilateral and contralateral finding. Biomed Pap Med Fac Univ Palacky Olomouc Czech Repub pp. 163.

39. Zrenner E, Bartz Schmidt KU, Benav H, Besch D, Bruckmann, et al. (2011) Subretinal electronic chips allow blind patients to read letters and combine them to words. Proc R Soc 278: 1489-1497.

40. Bloome MA, Garcia ChA (1982) Manual of retinal and choroidal dystrophies. Appleton-Century-Crofts 129: 0838561268

41. Ohno N, Murai H, Suzuki Y, Kiyosawa M, Tokumaru AM, et al. (2015) Alteration of the optic radiations using diffusiontensor MRI in patients with retinitis pgmentosa. Br J Ophthalmol 99(8): 1051-1054

42.42. Schoth F, Burgel U, Dorsch R, Reinges MH, Krings T, et al. (2006) Diffusion tensor imaging in acquired blind humans. Neurosci Lett 398(3): 178-182

43. Lestak J, Kyncl M, Tintera J (2019) Bionic Eye and Retinitis Pigmentosa. Biomed J Sci \& Tech Res 19: 14347-14348.

44. Castaldi E, Cicchini GM, Falsini B, Binda P, Morrone MC (2019) Visual Responses in Patients With Retinitis Pigmentosa Revealed by Functional Magnetic Resonance Imaging. Transl Vis Sci Technol 188(6): 44.

45. Castaldi E, Cicchini GM, Cinelli L, Biagi L, Rizzo S, et al. (2016) Visual BOLD Response in Late Blind Subjects with Argus II Retinal Prosthesis. PLoS Biol 14(10): e1002569.

46. Machado RA, Pereira CA, Ferreira F, Ferreira S, Quendera B, Silva E, et al. (2017)Structure-function correlations in Retinitis Pigmentosa patients with partially preserved vision: a voxel-based morphometry study. Sci Rep.12: 7(1): 11411
47. Kim SY, Sadda S, Humayun MS, de Juan E, Melia BM, et al. (2002) Morphometric analysis of the macula in eyes with geographic atrophy due to age-related macular degeneration. Retina 22(4): 464-470.

48. Medeiros NE, Curcio CA (2001) Preservation of ganglion cell layer neurons in age-related macular degeneration. Invest Ophthalmol Vis Sci 42(3): 795-803.

49. Lestak J, Tintera J, Karel I, Svata Z, Rozsival P, et al. (2013) FMRI in Patients with Wet Form of Age-Related Macular Degeneration. NeuroOphthalmology 37(5): 192-197.

50. Lestak J, Tintera J, Svata Z, Ettler L, Rozsival P, et al. (2014) Glaucoma and CNS. Comparison of FMRI-Results in Hypertension and Normal Tension Glaucoma. Biomed Pap Med Fac Univ Palacky Olomouc Czech Repub 158: 144-153.

51. Bloch E, Luo Y, da Cruz L (2019) Advances in retinal prosthesis systems. The Adv Ophthalmol p. 11.

52. Philip M, Lewis PM, Ackland HM, Lowery AJ, Rosenfeld JV, et al. (2015) Restoration of vision in blind individuals using bionic devices: A review with a focus on cortical visual prostheses. Brain Research 1595: 51-73.

53. Fernandes RA, Diniz B, Ribeiro R, Humayun M (2012) Artificial vision through neuronal stimulation. Neuroscience Letters 519(2): 122-128.

54. Humayun MS, Dorn JD, da Cruz L, Dagnelie G Sahel JA (2012) Interim results from the international trial of Second Sight's visual prosthesis. Ophthalmology 119: 779-788.

55. Richard G, Feucht M, Bornfeld N, Laube T. Rössler G, et al. ( 2005) Multicenter study on acute electrical stimulation of the human retina with an epiretinal implant: clinical results in 20 patients. Invest Ophthalmol Vis Sci 46(13): 1143

56. Keseru M, Feucht M, Bornfeld N, Laube T Walter P(2012) Acute electrical stimulation of the human retina with an epiretinal electrode array. Acta Ophthalmol 90(1): 1-8.

57. Humayun MS, Dorn JD, da Cruz L, Dagnelie G, Sahel JA, et al. (2012) Interim results from the international trial of Second Sight's visual prosthesis. Ophthalmology 119(4): 779-788.

58. Walter P (2016) A fully intraocular approach for a bi-directional retinal prosthesis. 151-161.

59. Rizzo JF, Shire DB, Kelly SK, Trozk P (2011) Development of the Boston retinal prosthesis. Conf Proc IEEE Eng Med Biol Soc 3135-3138.

60. Pardue MT, Phillips MJ, Yin H, Fernandes A (2005) Possible sources of neuroprotection following subretinal silicon chip implantation in RCS rats. J Neural Eng 2(1): 39-47

61. Pardue MT, Phillips MJ, Yin H, Sippy BD, Webb Wood S, et al. (2005) Neuroprotective effect of subretinal implants in the RCS rat. Invest Ophthalmol Vis Sci 46(2): 674-682

62. Zrenner E, Bartz Schmidt KU, Besch D, Gekeler F Koitschev A, et al. (2016) The subretinal implant ALPHA: implantation and functional results. Artificial vision 65-83.

63. Lee DY, Lorach H, Huie P, Palanker D (2016) Implantation of modular photovoltaic subretinal prosthesis. Ophthalmic Surg Lasers Imaging Retina 47(2): 171-174.

64. Wang L, Mathieson K, Kamins TI, Loudin JD, Galambos L, et al. (2012) Photovoltaic retinal prosthesis: implant fabrication and performance. J Neural Eng 9(4): 046014.

65. Lorach H, Palanker D (2016) High resolution photovoltaic subretinal prosthesis for restoration of sight. Artificial vision 115-124.

66. Saunders AL, Williams CE, Heriot W, Briggs R, Yeoh J, et al. (2014) Development of a surgical procedure for implantation of a prototype suprachoroidal retinal prosthesis. Clin Exp Ophthalmol 42(7): 665-674. 
67. Shivdasani MN, Yeoh J, McCombe MF, Briggs RJ, Opie NL, et al. (2014) First-in-human trial of a novel suprachoroidal retinal prosthesis. Plos one 9(12): e115239.

68. Ayton LN, Suaning GJ, Lovell NH, Petoe MA, Nayagam DAX, et al. (2016) Suprachoroidal retinal prostheses. Artificial vision 125-138.

69. Sinclair NC, Shivdasani MN, Perera T, Gillespie LN, McDermott HJ, et al. (2016) the appearance of phosphenes elicited using a suprachoroidal retinal prosthesis. Invest Ophthalmol Vis Sci 57(11): 4948-4961.

70. Petoe MA, McCarthy CD, Shivdasani MN, Sinclair NC, Scott AF, et al. ( 2017) Determining the contribution of retinotopic discrimination to localization performance with a suprachoroidal retinal prosthesis. Invest Ophthalmol Vis Sci 58(7): 3231-3239.

71. Shivdasani MN, Sinclair NC, Gillespie LN, Petoe MA, Titchener SA, et al. (2017) Identification of characters and localization of images using direct multiple-electrode stimulation with a suprachoroidal retinal prosthesis. Invest Ophthalmol Vis Sci 58(10): 3962-3974.
72. Fujikado T, Kamei M, Sakaguchi H, Kanda H, Morimoto T, et al. (2011) Testing of semichronically implanted retinal prosthesis by suprachoroidal-transretinal stimulation in patients with retinitis pigmentosa. Invest Ophthalmol Vis Sci 52(7): 4726-4733.

73. Fujikado $\mathrm{T}$ (2016) Retinal prosthesis by suprachoroidal-transretinal stimulation (STS), Japanese approach. In: Gabel VP, [Ed.,] Artificial vision. Cham: Springer 139-150.

74. Fujikado T, Kamei M, Sakaguchi H, Kanda H, Endo T, (2016) Oneyear outcome of 49-channel suprachoroidal-transretinal stimulation prosthesis in patients with advanced retinitis pigmentosa. Invest Ophthalmol Vis Sci 57(14): 6147-6157.

75. Endo T, Fujikado T, Hirota M, Kanda H, Morimoto T, et al. (2018) Light localization with low-contrast targets in a patient implanted with a suprachoroidal-transretinal stimulation retinal prosthesis. Graefes Arch Clin Exp Ophthalmol 256(9): 1723-1729. 